\title{
Método self-bealing como estratégia de promoção à saúde e reabilitação de pessoas com esclerose múltipla no contexto da terapia ocupacional ${ }^{1}$
}

\author{
Paula Pozzi Pimentel, Rosé Colom Toldrá
}

Departamento de Fisioterapia, Fonoaudiologia e Terapia Ocupacional, Faculdade de Medicina FMUSP,

Universidade de São Paulo, São Paulo, SP, Brasil.

\begin{abstract}
Resumo: Introdução: A esclerose múltipla, doença neurológica crônica, de evolução contínua e diferenciada, demanda autoconhecimento do corpo, para melhor percepção das capacidades preservadas, das perdas gradativas e da repercussão na realização das atividades e na participação social. Objetivo: Analisar a experiência grupal de aplicação das técnicas corporais baseadas no método self-healing, para a promoção da saúde e reabilitação de pessoas com esclerose múltipla, desenvolvida pela terapia ocupacional. Método: Pesquisa qualitativa do tipo documental referente aos registros escritos e áudios transcritos das sessões grupais. Para análise dos dados foi utilizado o método do Discurso do Sujeito Coletivo. Resultados: Participaram do grupo terapêutico 10 adultos com esclerose múltipla, com idades e tempos de doença variados. Foram identificados cinco discursos relacionados às representações e experiências decorrentes da doença e dos efeitos do aprendizado das técnicas corporais do método self-healing. Como benefícios destacam-se maior percepção corporal, diminuição dos sintomas, melhora da capacidade funcional e reconhecimento da necessidade da prática corporal na rotina. Conclusão: $\mathrm{O}$ uso terapêutico do método self-healing demonstrou sua aplicabilidade para a promoção da saúde e reabilitação, em conformidade com as políticas da saúde. Dada a pouca literatura existente sobre os benefícios do uso do método self-healing indica-se o desenvolvimento de novos estudos.
\end{abstract}

Palavras-chave: Esclerose Múltipla, Self-Healing, Terapias Mente-Corpo, Corpo Humano, Autocuidado, Terapia Ocupacional.

\section{Self-healing method as strategy to promote health and rehabilitation of people with multiple sclerosis in the context of occupational therapy}

\begin{abstract}
Introduction: Multiple sclerosis is a neurological chronic disease with continuous and differentiated evolution, it demands body self-knowledge for better understanding of preserved capacities, gradual losses and repercussion in the performance of activities and social participation. Objective: To analyze the group experience of the application of physical techniques based on self-healing method for health promotion and rehabilitation of people with multiple sclerosis, developed by Occupational Therapy. Method: Documental qualitative research referring to written records and audio transcripts of group sessions. Data analysis used the Collective Subject Discourse method. Results: Ten adults with multiple sclerosis, with varying ages and disease times, participated in the therapeutic group. Five participants reported representations and experiences due to the disease and the effect of learning the physical techniques of self-sealing. The benefits include a greater body awareness, decreased symptoms, improved functional capacity and recognition of the need of body practice routine. Conclusion: The therapeutic use of self-healing method demonstrated its applicability to promote the health benefits, rehabilitation, according to health policies. Due to limited literature on the benefits of using the self-healing method indicates the development of new studies.
\end{abstract}

Keywords: Multiple Sclerosis, Self-Healing, Mind-Body Therapies, Human Body, Self-Care, Occupational Therapy. 


\section{Introdução}

Esclerose múltipla (EM) é uma doença do sistema nervoso central (SNC) que se caracteriza por um processo infamatório na substância branca, com formação de tecido fibroso cicatricial denominado placas escleróticas, que causa redução da condução do impulso nervoso com danos permanentes ou transitórios em qualquer área do SNC (CALLEGARO; LINO; MARCHIORI, 2009). O curso da doença é heterogêneo e imprevisível e os sintomas principais são: fraqueza muscular, fadiga, dor, espasticidade, alteraçôes da sensibilidade e da cognição, depressão, alteraçôes visuais e esfincterianas (CALLEGARO; LINO; MARCHIORI, 2009). A doença apresenta duas formas distintas de evolução: a forma remitente recorrente, mais comum, que se caracteriza por surtos e remissão, e a forma progressiva (CALLEGARO; LINO; MARCHIORI, 2009).

As características e os sintomas da EM demandam autoconhecimento do próprio corpo por parte $\mathrm{da}$ pessoa devido às constantes alteraçóes na funcionalidade, que requerem uma melhor percepçâo das capacidades preservadas e das perdas gradativas identificadas na realização das atividades cotidianas (TOLDRÁ, 2005). Dessa forma, as pessoas com EM se deparam com a constante necessidade de renegociação com seu próprio corpo (TOLDRÁ; SOUTO; PIMENTEL, 2013), consequência de um processo resultante de um corpo que reage, muitas vezes, de forma surpreendente (CALLEGARO; LINO; MARCHIORI, 2009; SCHNEIDER; LARKIN; SCHNEIDER, 1999), somado ao enfrentamento de aspectos ambientais e atitudinais nem sempre favoráveis. Tais fatores justificam a importância do desenvolvimento de estratégias terapêuticas que promovam o autoconhecimento do corpo, para minimizar as perdas, seu impacto no cotidiano e promover o cuidado com a saúde (TOLDRÁ, 2005).

Dado o reconhecimento que as doenças crônicas influenciam não somente a funcionalidade, mas também o contexto social e pessoal, a atenção voltada a essas pessoas deve ser capaz de abranger tais aspectos (TOLDRÁ, 2005). Assim, o acompanhamento terapêutico ocupacional de forma grupal pode se apresentar como uma estratégia de intervenção eficaz de reabilitação e de superação das limitaçôes decorrentes da própria deficiência, na medida em que estimula a troca de aprendizados e experiências sobre práticas de autocuidado entre as pessoas (ANTONIO; TOLDRÁ, 2015), bem como potencializa o uso de diferentes estratégias terapêuticas (TAVARES et al., 2012).
O estímulo ao autocuidado contribui para um melhor uso das funçóes corporais, o que possibilita a promoção da saúde, bem-estar e prevenção das incapacidades (TOLDRÁ et al., 2014). Nesse sentido, as práticas corporais são consideradas ferramentas para o desenvolvimento de açóes de autocuidado (BRASIL, 2010), na medida em que propiciam uma melhor apropriaçáo do próprio corpo e o desenvolvimento da autopercepção pela pessoa (TOLDRÁ et al., 2014).

De acordo com a Política Nacional de Promoção da Saúde, as práticas corporais são reconhecidas como possibilidades de organização, escolhas nos modos de relacionar-se com o corpo e de movimentar-se, por isso compreendidas como recursos eficientes no cuidado à saúde, na medida em que podem agregar um conjunto de açôes voltadas para o cuidado corporal, multiplicando as possibilidades de ação sobre ele (BRASIL, 2010). Tal perspectiva enfatiza o conceito ampliado de saúde e analisa o processo saúde-doença articulado com as demais políticas e práticas (BRASIL, 2010). Porém, observa-se nos serviços públicos de saúde uma falta de informação e desconhecimento, tanto dos profissionais da saúde quanto dos usuários dos serviços, sobre possibilidades do uso das práticas corporais (BRASIL, 2010). Agrega-se a isso a necessidade do desenvolvimento de práticas, direcionadas para a promoção da saúde, prevenção e resolubilidade das demandas do usuário, por meio do vínculo e da responsabilização (MALTA; MERHY, 2010), que podem ser favorecidas por meio de práticas voltadas ao cuidado corporal.

Verifica-se que a atenção dedicada ao próprio corpo pela maioria das pessoas é limitada tanto em relação à consciência das suas sensaçóes físicas quanto das emocionais (SCHNEIDER; LARKIN; SCHNEIDER, 1999; TOLDRÁ, 2005; FERRIGNO, 1990). No entanto, o corpo é o meio pelo qual percebemos o mundo, estabelecemos nossas açôes, relações e o construímos através da experiência, pois é no fazer que o corpo se faz (SAITO; CASTRO, 2011; ALMEIDA, 2004). A condição de existência do corpo envolve a percepção do mesmo em seu meio, identificação de estímulos, expressão do movimento dos outros corpos e objetos, o que permite o conhecimento, bem como o reconhecimento do mundo, dos limites, das possibilidades, do prazer, da dor, dos sentidos, da inteligência, da sensibilidade e da motricidade (FERRIGNO, 1990).

A consciência do próprio corpo proporciona o conhecimento de si e a (re)descoberta de percepçóes não captadas ou esquecidas nas atividades cotidianas devido aos hábitos e à mecanização do fazer (SCHNEIDER; LARKIN; SCHNEIDER, 1999; 
TOLDRÁ, 2005). As práticas corporais, além de promoverem a consciência corporal, possibilitam maior sensibilidade e aprendizado de como reagir ao ambiente, pois estimulam o córtex motor a reconhecer novas formas de ação, modificando os padróes de movimento habituais, novos meios de operar e estar no mundo (SAITO; CASTRO, 2011).

Para Meir Schneider, criador do método corporal denominado self-healing $(\mathrm{SH})$ nos anos 70, a consciência cinestésica é a consciência física e sensorial do corpo, ou seja, é a capacidade de poder sentir, cada vez mais, o que acontece com o corpo tanto interna como externamente (SCHNEIDER; LARKIN; SCHNEIDER, 1999). No caso da EM, a consciência cinestésica facilita a (re)conexão entre a mente e o corpo, que pode estar fragilizada devido ao processo de adoecimento.

Segundo o autor, o movimento do corpo é inerente ao ser humano e se constitui em seu próprio uso, por isso considerado uma das ferramentas mais versáteis para o cuidado corporal e fundamental à vida (SCHNEIDER; LARKIN; SCHNEIDER, 1998). Com o movimento é possível desenvolver o diálogo corpo-mente e, consequentemente, o autoconhecimento e a manutenção da capacidade funcional do indivíduo (SCHNEIDER; LARKIN; SCHNEIDER, 1998; TOLDRÁ, 2005).

As diversas técnicas de movimento, respiração, visualizaçáo e massagem do método self-healing, podem ser aplicadas na prevenção e reabilitação de várias doenças (orgânicas, físicas e visuais) na medida em que estimulam e equilibram as funçôes orgânicas, físicas e psíquicas por meio de informaçōes e percepções de como o corpo funciona, reage e pode melhorar (SCHNEIDER; LARKIN; SCHNEIDER, 1999; SCHNEIDER, 2005). Com a prática dessas técnicas é possível adquirir melhores hábitos corporais, que podem resultar em bem-estar físico, vitalidade e longevidade (SCHNEIDER; LARKIN; SCHNEIDER, 1999; SCHNEIDER, 2005; MENEGHIN; REIS; SOARES, 2006).

O método destaca a importância de abandonar os medos e as defesas, olhar para si e perceber o que impede a adoção das técnicas no dia a dia pela pessoa (BAMBRIDGE, 2002). Desta forma a aplicação das várias técnicas do método self-healing amplia o arsenal de recursos para a pessoa lidar com sua doença e favorecer o autocuidado (TUROLLA; GEBRAEL; NASCIMENTO, 2015).

$\mathrm{O}$ atendimento da terapia ocupacional com o uso das práticas corporais, a partir do método self-healing, mostra-se apropriado para as pessoas com EM (TOLDRÁ, 2005; TOLDRÁ; SOUTO;
PIMENTEL, 2013). Assim, os movimentos leves e sutis, realizados sem esforço e de forma consciente, proporcionam o desenvolvimento da consciência cinestésica (SCHNEIDER; LARKIN; SCHNEIDER, 1999), uma vez que requerem a atençáo direcionada para a região do corpo, articulação ou órgão interno em atividade, o que favorece a conexão da transmissão neurológica e a utilização do grupo muscular requisitado de forma mais equilibrada (TOLDRÁ et al., 2014). Destaca-se que os efeitos do uso das técnicas do método estimulam a circulação sanguínea, o alívio de tensôes, a percepção do movimento, a diminuição ou até a eliminaçáo de padróes que favoreçam o aparecimento de sintomas de doenças e agravos à saúde (SCHNEIDER; LARKIN; SCHNEIDER, 1999; SCHNEIDER, 2005; TOLDRÁ, 2005; TOLDRÁ et al., 2014).

A terapia ocupacional e o método self-healing têm como premissa que o trabalho conjunto entre usuário-terapeuta e a relação dual e integrada corpo-mente possibilitam que as pessoas atendidas sejam protagonistas nos seus processos de reabilitação e na melhora da qualidade de vida (SCHNEIDER; LARKIN; SCHNEIDER, 1999; TOLDRÁ, 2005; MENEGHIN; REIS; SOARES, 2006). Nesse contexto, a pessoa é considerada como o principal agente transformador de sua condição de saúde (FERRIGNO, 1990) na medida em que a atenção é referenciada no vínculo e na responsabilização (MALTA; MERHY, 2010).

Como base nos aspectos citados acima, o presente trabalho analisa a experiência de grupo terapêutico com aplicação das técnicas corporais baseadas no método self-healing, para a promoção da saúde e reabilitação de pessoas com EM na atenção à saúde de média complexidade, sob a orientação da terapia Ocupacional. Esse âmbito de atenção, de acordo com o Sistema Único de Saúde, preconiza promoção da saúde, prevençáo das doenças ou danos, tratamento e reabilitaçáo visando o autocuidado (BRASIL, 2007).

\section{Método}

Trata-se de estudo qualitativo, do tipo descritivo (GIL, 2006), referente à análise documental do projeto "Grupo de Promoção da Saúde de Pessoas com Esclerose Múltipla”, desenvolvido pela terapia ocupacional, no Centro de Docência e Pesquisa do Departamento de Fisioterapia, Fonoaudiologia e Terapia Ocupacional, Faculdade de Medicina da Universidade de São Paulo (FMUSP). Este estudo faz parte de pesquisa aprovada pelo Comitê de Ética em Pesquisa da FMUSP no 243/11. Todos os participantes assinaram o Termo de Consentimento 
Livre e Esclarecido depois do aceite de participação no grupo.

Os integrantes do grupo eram acompanhados no Instituto Central do Hospital das Clínicas e foram contatados a partir de um banco de dados de 115 pessoas com EM, por meio telefônico. Estes possuíam a forma Remitente Recorrente da doença e pontuação da Escala Expandida do Estado de Incapacidade de Kurtzke (EDSS) com grau de 0 a 5 , correspondente a nenhuma incapacidade até incapacidade moderada, a qual afeta as atividades diárias, porém com independência para a sua realização (CALLEGARO; LINO; MARCHIORI, 2009).

O grupo se reuniu semanalmente, no decorrer de seis meses entre 2012 e 2013, totalizando vinte e dois encontros, com uma hora e meia de duração. Foram feitos registros escritos e de áudio (aparelho MP3) das sessóes grupais, com autorização prévia dos participantes. O estudo documental foi realizado a partir da análise dos registros escritos e transcrição dos áudios derivados das sessôes grupais. No estudo documental considera-se qualquer material escrito usado como fonte de informaçáo referente ao comportamento humano (LÜDKE; ANDRÉ, 1988), nesse caso, os documentos gerados a partir dos registros dos atendimentos grupais realizados pela terapia ocupacional.

Para a organização e análise dos registros escritos, foi utilizado o método do Discurso do Sujeito Coletivo (DSC), o qual permite a recomposição de um pensamento coletivo a partir dos discursos individuais, dos quais são identificadas as expressões-chave e ideias centrais, que caracterizam e formatam o discurso coletivo (LEFÉVRE; LEFÉVRE, 2003). Esta estratégia discursiva visa explicitar uma dada representação social, bem como o conjunto das representaçóes que formam o imaginário social (LEFÉVRE;
LEFÉVRE, 2003), nesse caso, correspondente às vivências dos participantes do grupo com a prática do método self-healing.

A realização do estudo seguiu as etapas: 1- transcrição dos registros em áudio realizados durante os encontros grupais; 2- leitura dos registros escritos e transcritos; 3- submissão desses registros a um trabalho analítico inicial de decomposição, para extrair as expressóes chaves e as ideias centrais presentes em cada um dos discursos individuais; 4- elaboração do discurso-síntese através dos diferentes depoimentos, que corresponde ao DSC. Conforme o método, os discursos sáo apresentados em itálico e na primeira pessoa no singular, para indicar a pessoa falando (LEFÉVRE; LEFÉVRE, 2003).

\section{Resultados}

O grupo foi composto por 10 pessoas adultas diagnosticadas com EM, sendo a maioria mulheres, com idades entre 23 e 55 anos. O tempo de doença variou entre 1 e 13 anos. Quanto à escolaridade, o grupo apresentava heterogeneidade entre ensino médio completo e superior completo. Em relação ao estado civil, seis pessoas eram casadas, duas solteiras e duas divorciadas. Quanto à ocupação dos membros do grupo, cinco eram empregados, um do lar e quatro aposentados, por invalidez devido à doença, conforme Tabela 1 .

$\mathrm{Na}$ dinâmica das sessóes grupais, o primeiro momento foi voltado às questôes disparadoras que orientavam as conversas e as trocas de experiências sobre temas relacionados a: tratamentos e vivências com a doença; atividades realizadas e orientações; desafios para o aprendizado e prática do método self-healing e benefícios alcançados. Na sequência, esse ambiente preparava o grupo para a experimentação

Tabela 1. Características sócio demográficas dos participantes do Grupo de Promoção da Saúde de Pessoas com Esclerose Múltipla. São Paulo, 2016.

\begin{tabular}{cccccccc}
\hline $\begin{array}{c}\text { Participantes } \\
\text { do grupo }\end{array}$ & Sexo & Idade & Estado civil & Escolaridade & Ocupação & $\begin{array}{c}\text { Tempo de } \\
\text { doença }\end{array}$ & Edss \\
\hline A & F & 23 & Casada & Ens. Médio Comp. & Do lar & 1 & 2 \\
B & M & 28 & Casado & Ens. Sup. Incomp. & Aposentado & 7 & 2 \\
C & M & 30 & Casado & Ens. Sup. Comp. & Empregado & 5 & 0.5 \\
D & F & 30 & Casada & Ens. Médio Comp. & Autônoma & 6 & 0 \\
E & M & 36 & Solteiro & Ens. Sup. Comp. & Empregado & 13 & 1 \\
F & F & 41 & Solteira & Ens. Sup. Comp. & Aposentada & 10 & 4.5 \\
G & F & 44 & Divorciada & Ens. Sup. Comp. & Aposentada & 19 & 4 \\
H & F & 50 & Casada & Ens. Médio Comp. & Empregada & 7 & 2 \\
I & F & 53 & Divorciada & Ens. Sup. Incomp. & Empregada & 5 & 1 \\
J & F & 55 & Casada & Ens. Médio Comp. & Aposentada & 5 & 2 \\
\hline
\end{tabular}


corporal com base nas técnicas do método self-healing, tais como: movimentos suaves e coordenados, técnicas de visualização, respiração, automassagem e relaxamento.

O estudo documental realizado a partir de leituras e análises dos registros das sessóes grupais permitiu a categorizaçáo de cinco diferentes Ideias Centrais (IC): $1^{\text {a }}$ IC - Os impactos da EM no dia a dia; 2a IC - O grupo e o cuidado: tenho muitas experiências e aprendizados com o grupo; $3^{\mathrm{a}} \mathrm{IC}$ - A prática das técnicas do método self-healing: parece que você tem um domínio maior do seu corpo; $4^{\mathrm{a}} \mathrm{IC}$ - Eu vejo a importância da prática corporal no meu dia a dia; $5^{a}$ - Tem que introduzir na rotina. Tais ICs correspondem a cinco DSCs, conforme apresentado na Tabela 2. Os discursos revelaram às vivências e as dificuldades oriundas da doença bem como as experiências e os benefícios provenientes das práticas corporais orientadas pelo método self-healing, desenvolvidos no "Grupo de Promoção da Saúde de Pessoas com Esclerose Múltipla”.

\section{Discussão}

A diversidade das características dos componentes do grupo quanto à idade, tempo de doença e grau de incapacidade medido pelo EDSS potencializou as oportunidades de trocas, de vivências e de aprendizado das técnicas do método self-healing no grupo. Com isso, os participantes demonstraram a identificação de questôes singulares decorrentes do próprio universo de significados, valores e atitudes, o que favoreceu que a estratégia discursiva explorasse com maior clareza as representaçôes sociais e a produção de um discurso representativo sobre a experiência dos participantes do grupo, conforme preconizado pelo método (LEFÉVRE; LEFÉVRE, 2003).

Dessa forma foi possível reconhecer, pela fala dos participantes do grupo, as vivências decorrentes da EM, bem como a importância e a validade do uso das técnicas corporais do método self-healing desenvolvido no contexto grupal pela terapia ocupacional. As questôes disparadoras adotadas fomentaram a dinâmica de experimentação corporal de forma grupal e apoiaram a socialização das experiências com a doença, a percepçáo das incapacidades e seu impacto no dia a dia, conforme identificado:

A fadiga é um dos principais sintomas, fico cansado muito facilmente, sinto muita fraqueza, como se a perna estivesse se arrastando... Também tenho dormência e falta de sensibilidade nas mãos (1ํ DSC).
O emprego da estratégia de atenção grupal preconizada pelas políticas de saúde (BRASIL, 2010; SANTOS et al., 2006) e amplamente valorizada pelos terapeutas ocupacionais (SAMEA, 2008; BALLARIN, 2007; CALDEIRA; MONTILHA; NOBRE, 2003; BRUNELLO, 2002; ANTONIO; TOLDRÁ, 2015; TAVARES et al., 2012) mostrou-se adequada para despertar o desejo de mudanças atitudinais, para a promoção de cuidados com a saúde no dia a dia, pelo efeito positivo de compartilhamento entre os participantes (ANTONIO; TOLDRÁ, 2015; TOLDRÁ et al., 2014). O grupo colaborou para romper com o isolamento que as pessoas com doenças crônicas, geralmente, vivem e se transformou em um espaço educativo, de aprendizagem, de ajuda, de expressão dos sentimentos e ampliação da rede social de suporte (TAVARES et al., 2012; ANTONIO; TOLDRÁ, 2015), como demonstrado:

\section{[...] tenho muitas experiências e aprendizados adquiridos com o grupo... As pessoas com EM deveriam ter mais acesso a tratamentos como os recebidos nesse grupo (2。 DSC).}

Verifica-se que é fundamental um ambiente favorável para a expressão das pessoas que vivenciam situaçóes de incapacidade e restrição na participação das atividades do cotidiano. A oportunidade de vivência coletiva e solidária propiciou a ressignificação do diagnóstico, desenvolvimento e aprendizado de estratégias de cuidado com a saúde e formas mais saudáveis de enfrentamento dos sintomas e incapacidades. Também, os participantes puderam manifestar e processar mobilizaçôes emocionais e construir relaçôes sociais cooperativas na perspectiva do desenvolvimento da autonomia (SANTOS et al., 2006) e da participação social, tal como destacado a seguir:

Gostei de conhecer outras pessoas com EM... O grupo ajuda pensar melhor sobre a doença... é importante esse diálogo ( $\left.2^{\circ} \mathrm{DSC}\right)$.

Assim, as práticas corporais em grupo ampliam as possibilidades de encontrar, escutar, observar e mobilizar as pessoas para que, no processo de cuidado com o corpo, possam construir relaçóes de vínculo e de corresponsabilidade de forma autônoma (CARVALHO, 2006). Tal ambiente favorece dar sentido à aprendizagem e às mudanças que devem ser empreendidas para o autocuidado (TAVARES et al., 2012) na rotina de vida dos participantes e para uma melhor compreensão do processo saúde-doença.

Para a terapia ocupacional, as práticas corporais são consideradas potentes instrumentos de modificação do cotidiano das pessoas, dado que as experiências 
Tabela 2. IC e DSCs dos participantes do Grupo de Promoção da Saúde de Pessoas com Esclerose Múltipla. São Paulo, 2016.

\section{$1^{a}$ IC - Os impactos da EM no dia a dia}

$\mathbf{1}^{\circ}$ DSC A EM me deixou numa cadeira de rodas... Tive incontinência urinária. Hoje já estou melhor, mas passei por um periodo no qual usei fraldas... Ainda incomoda bastante. Isso também prejudica o sono... No meu primeiro surto, além de dores fortíssimas, parei de enxergar.. Sempre sinto muita dor de cabeça, geralmente relacionadas com a fadiga e o estresse, quando alguma coisa sai da rotina... Tenho dificuldade de guardar as coisas. A gente tem muita tarefa no dia, e quer fazer tudo... A fadiga é um dos principais sintomas, fico cansado muito facilmente, sinto muita fraqueza, como se a perna estivesse se arrastando... Também tenho dormência e falta de sensibilidade nas mãos... Sou muito descoordenado, tenho dificuldade de perceber meu corpo no espaço e sempre acabo esbarrando nos objetos...

\section{$2^{\mathrm{a}}$ IC - O grupo e o cuidado: tenho muitas experiências e aprendizados com o grupo}

$\mathbf{2}^{\circ}$ DSC Sempre busco novas alternativas para me relacionar melhor com a EM, por isso aceitei participar do grupo. Gostei de conhecer outras pessoas com EM... O grupo ajuda pensar melhor sobre a doença... Quanto mais à gente fala das dificuldades, é mais fácil para o profissional saber o que você precisa... é importante esse diálogo... Eu gosto muito... a terapia ocupacional ajuda muito... Está sendo muito bom, era o que eu precisava... Os exercícios que aprendi no grupo melhoraram muito a minha qualidade de vida... Quem tem EM deveria fazer esse tipo de tratamento... A questão é onde encontrar... Agora, tenho muitas experiências e aprendizados adquiridos com o grupo... As pessoas com EM deveriam ter mais acesso a tratamentos como os recebidos nesse grupo ...

$3^{\mathrm{a}}$ IC - Prática das técnicas do método self-healing: parece que você tem um domínio maior do seu corpo $\mathbf{3}^{\circ}$ DSC Esses movimentos do SH ajudam muito no equilibrio... antes de aprender e praticar, eu não utilizava as duas pernas de maneira equilibrada, sempre exigia mais de uma perna do que da outra... Com os exercícios, parece que você tem um dominio maior do seu corpo... Conseguir focar e prestar atenção... traz consciência do corpo...dá pra perceber quais os músculos que são necessários para os movimentos... iguala à sensação do corpo, alcança o equilibrio e o corpo fica preparado. Sinto mais facilidade ao andar, mais ágil... Também aprendi a visualizar para andar, para pegar as coisas... com a visualização o movimento, fica mais fácil... Parece que você tem um domínio maior do seu corpo... As batidinhas aumentam a circulação e fica mais fácil movimentar, dá mais segurança e equilibrio... Parece que não, mas a gente vê a diferença... A respiração profunda trabalha mente e corpo... principalmente quando se pensa as coisas que se quer fazer junto com a respiração... No meu dia a dia, me sinto mais leve quando faço os exercícios. Isso também significa respeitar mais o corpo, quando me canso, paro. Quando faço mais pausas realizo as atividades com maior facilidade e fico menos fatigado.

\section{$4^{\mathrm{a}}$ IC Eu vejo a importância da prática corporal no meu dia a dia}

$4^{\circ}$ DSC Depois que comecei a praticar os movimentos e as orientações, tenho períodos mais estáveis e com surtos mais brandos na perna... Com a prática das orientações e dos movimentos você percebe seu corpo muito melhor, reconhecendo os momentos de picos energéticos e consegue se manter mais estável e sentir menos fadiga... Agora eu sei quando devo poupar energia... quando me canso, paro... faço mais pausas e realizo as atividades com maior facilidade e menos fatigado.Isso também significa respeitar mais o corpo. Aprendi a me concentrar e a me relacionar com o meu próprio corpo. Percebi que o corpo não é uma máquina... Esses exercicios que aprendi no grupo melhoraram muito a minha qualidade de vida. Conheço-me melhor agora. Eu vejo a importância da prática corporal no meu dia a dia e na maneira de lidar com a doença.

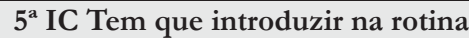

$5^{\circ}$ DSC É um cuidado que exige dedicação... Tem que introduzir na rotina... Além das práticas corporais, aprendi nesse grupo, a importância de se programar e organizar minhas atividades ao longo do dia... Minha vida melhorou de 70 a 80\% porque passei a me programar... Temos que fazer as coisas com intenção, consciência... Acordo mais cedo e visualizo todas as tarefas que tenho que realizar naquele dia e isso me faz muito bem... como algo tão simples faz diferença e é eficiente. Antes de levantar, dou aquelas batidinhas para acordar as pernas... Acho melhor fazer os movimentos pela manhã do que à tarde. Também faço no metrô, na fila do ônibus...

do próprio sujeito favorecem a apropriação de si, do cuidado e da produção de saúde (SAITO; CASTRO, 2011).

Ademais, a frequente necessidade de renegociação com o próprio corpo, vivenciado pelas pessoas com EM (TOLDRÁ; SOUTO; PIMENTEL, 2013), causam desafios para o terapeuta ocupacional na busca de estratégias terapêuticas. Assim, o método self-healing, por meio da aplicação das diversas técnicas, proporciona a ampliação do potencial das pessoas para o autoconhecimento, autocuidado (TUROLLA; GEBRAEL; NASCIMENTO, 2015), promoção da saúde e de melhor qualidade de vida, conforme a seguir:

A terapia ocupacional ajuda muito... Está sendo muito bom, era o que eu precisava... Os exercícios que aprendi no grupo melhoraram muito a minha qualidade de vida (2० DSC). 
O processo grupal favoreceu a associaçáo de técnicas terapêuticas (TAVARES et al., 2012). Assim, juntamente com o aprendizado corporal desenvolvido por meio das técnicas do método self-healing, foram exploradas estratégias relacionadas à fadiga, prevenção de quedas e orientaçóes para as atividades do dia a dia, conforme segue:

Esses movimentos do SH ajudam muito no equilibrio... antes de aprender e praticar, eu não utilizava as duas pernas de maneira equilibrada, sempre exigia mais de uma perna do que da outra (3० DSC).

Na perspectiva do método, o desenvolvimento da consciência do movimento corporal traz mobilidade para as regióes do corpo que apresentam rigidez, bem como melhora a função dos sistemas corporais de forma geral e, quando associado às diferentes técnicas, amplifica os efeitos terapêuticos (SCHNEIDER; LARKIN; SCHNEIDER, 1998; SCHNEIDER, 2005). Conforme o $3^{\circ}, 4^{\circ}$ e $5^{\circ}$ DSCs, ficam destacadas a utilização das diferentes técnicas no dia a dia e os efeitos percebidos pelos participantes do grupo.

A prática das técnicas do método self-healing favorece a percepção do próprio corpo, o desenvolvimento da consciência cinestésica e a acuidade para perceber os efeitos dos movimentos corporais e das atividades do dia a dia, identificados a seguir:

Dá pra perceber quais os músculos que são necessários para os movimentos... iguala a sensação do corpo, alcança o equilibrio e o corpo fica preparado (3० DSC).

O efeito da consciência cinestésica estimula o sistema nervoso central e periférico, na medida em que se pratica movimentos lentos, coordenados e de formas diferentes com o corpo, em comparação com as técnicas habituais (SCHNEIDER; LARKIN; SCHNEIDER, 1998).

A respiraçáo profunda e lenta, outra técnica do método, explora a autopercepção, identificação das necessidades e limites do próprio corpo, que em conjunto com os movimentos corporais, promove a percepção cinestésica, ou seja, a consciência do movimento (TOLDRÁ et al., 2014). O aproveitamento dos conhecimentos adquiridos com a experimentaçâo do método fica evidenciado no seguinte discurso:

A respiração profunda trabalha mente e corpo (3o DSC).

Já a visualização, como um ato mental, estimula os mesmos circuitos cerebrais usados para o ato físico (RATEY, 2002) e, quando integrado às demais técnicas, amplia os seus efeitos terapêuticos
(TOLDRÁ et al., 2014). Assim sendo, a visualização mental do movimento torna sua execução cada vez mais leve e realizada com menor esforço (SCHNEIDER; LARKIN; SCHNEIDER, 1998), identificada pelos participantes como estratégia que pode ser adotada na realização das atividades na rotina de vida, conforme demonstrado:

Aprendi a visualizar para andar, para pegar as coisas... com a visualização o movimento fica mais fácil (4º DSC).

Assim, o reconhecimento das capacidades corporais propiciadas pelas práticas aprendidas durante as sessóes grupais enfatiza o benefício para o autocuidado (ANTONIO; TOLDRÁ, 2015), conforme segue:

Com a prática das orientaçōes e dos movimentos você percebe seu corpo muito melhor, reconhecendo os momentos de picos energéticos e consegue se manter mais estável e sentir menos fadiga (4 DSC).

As discussōes e as experimentaçóes corporais ocorridas nos encontros grupais exploraram as estratégias de autocuidado e estimularam as pessoas a se tornarem agente da própria mudança, como exemplificado:

Vejo a importância da prática corporal no meu dia a dia e na maneira de lidar com a doença (40 DSC).

De forma geral verifica-se que as pessoas não identificam o impacto da normatizaçáo e dos padróes sociais no modo como expressam e sentem seu corpo nas situações da vida (FERRIGNO, 1990). Contudo, o atual modo de vida contribui para a dissociação entre a mente e o corpo e, portanto, à perda da consciência devido às influências sensoriais externas, obrigaçôes e ocupaçōes que obstruem a mente (SCHNEIDER; LARKIN; SCHNEIDER, 1998). Assim, o grupo também contribui para rever os valores vigentes como expressado:

Percebi que o corpo não é uma máquina (4º DSC).

Como proposto pelo método self-healing, é preciso reduzir o estresse do corpo como um todo, sendo um dos meios a realizaçáo de movimentos variados, conscientes e suaves (SCHNEIDER; LARKIN; SCHNEIDER, 1998; TUROLLA; GEBRAEL; NASCIMENTO, 2015). O terapeuta ocupacional, experto nas atividades humanas, pode favorecer a aplicação de uma diversidade de vivências de movimentos e de percepçôes do corpo integradas ao cotidiano, como demonstrado nos diferentes DSCs. 
O cuidado da saúde, especialmente no caso de doenças crônicas, envolve o desenvolvimento da corresponsabilidade da pessoa pelo próprio cuidado, bem como a autonomia nesse processo, para fortalecer escolhas responsáveis que implicarão na qualidade de vida (FERRIGNO, 1990; MALTA; MERHY, 2010; SCHNEIDER; LARKIN; SCHNEIDER, 1999; TOLDRÁ, 2005; MENEGHIN; REIS; SOARES, 2006). Assim, a intervenção terapêutico-ocupacional desenvolvida no grupo incluiu estratégias de orientação para a incorporação do método self-healing na rotina (TOLDRÁ, 2005; MENEGHIN; REIS; SOARES, 2006; TOLDRÁ et al., 2014; TUROLLA; GEBRAEL; NASCIMENTO, 2015), conforme demonstrado:

É um cuidado que exige dedicação... Tem que introduzir na rotina (5० DSC).

As vivências promovidas com as técnicas do método self-healing e associadas às orientaçôes de autocuidado, aprendidas nos encontros grupais, permitiram mudanças nos padróes de movimentos, na relaçáo com o próprio corpo e no estilo de vida, conforme expressado no seguinte discurso:

\section{Minha vida melhorou de 70 a $80 \%$ porque passei a me programar (5 DSC).}

Conforme refere a literatura de terapia ocupacional, as pessoas que possuem comprometimentos de saúde e limitaçôes físicas encontram, na prática do método self-healing, melhora da capacidade funcional, com desdobramentos na realização das atividades do cotidiano e na participaçáo social, proporcionando qualidade de vida (TOLDRÁ, 2005; TOLDRÁ; SOUTO; PIMENTEL, 2013; TOLDRÁ et al., 2014; TUROLLA; GEBRAEL; NASCIMENTO, 2015). O presente estudo corrobora com tais achados e destaca que o aprendizado e a prática corporal promovidos pelo método self-healing no contexto de terapia ocupacional favoreceram mudanças na rotina, que repercutiram em melhor percepção corporal, melhora das capacidades tanto físicas como mentais e estímulo para as práticas de autocuidado no dia a dia.

\section{Conclusão}

Dado que as práticas corporais estáo em conformidade com a formação do terapeuta ocupacional, esse profissional desponta como um dos membros da equipe de saúde capacitado para o desenvolvimento de açôes terapêuticas, que envolvam tais práticas para promoção da saúde e reabilitação nos diferentes contextos de atenção.
O estudo assinala que a proposta terapêutica em situaçáo grupal desenvolvida pela terapia ocupacional favoreceu o aprendizado da prática corporal baseada no método self-healing, na perspectiva do desenvolvimento da consciência corporal, do autocuidado, do gerenciamento de sintomas e na reorganização da rotina, o que se pode constatar pela manutençáo e/ou melhora tanto das capacidades físicas quanto mentais dos participantes do grupo.

Levando-se em conta os benefícios terapêuticos do uso do método self-healing, corroborados pelos participantes do grupo, as práticas corporais surgem como uma potente alternativa para a promoçáo da saúde, reabilitação e corresponsabilização da pessoa pelo cuidado à saúde, como preconizado pelas políticas da saúde. Isso justifica a importância do desenvolvimento de futuros estudos sobre a temática pela terapia ocupacional.

Como limite, destaca-se o fato do estudo de ter sido desenvolvido a partir de apenas um grupo. No entanto, dada a pouca literatura existente sobre os benefícios da aplicação do método self-healing pelo terapeuta ocupacional, aponta-se para a necessidade de realização de novos estudos, para identificação das potencialidades terapêuticas desse método em pessoas com EM, bem como em outras populaçôes.

\section{Referências}

ALMEIDA, M. V. M. Corpo e arte em terapia ocupacional. Rio de Janeiro: Enelivros, 2004.

ANTONIO, P. P.; TOLDRÁ, R. C. A estratégia grupal na reabilitaçáo de pessoas com acidente vascular cerebral: reflexôes sobre a prática da terapia ocupacional. Cadernos de Terapia Ocupacional da UFSCar, São Carlos, v. 23, n. 1, p. 43-52, 2015.

BALLARIN, M. L. G. S. Abordagens grupais. In: CAVALCANTI, A.; GALVÃO, C. (Org.). Terapia ocupacional: fundamentação \& prática. Rio de Janeiro: Guanabara Koogan, 2007. p. 38-43.

BAMBRIDGE, A. Approaching myopia holistically: a case study and theoretical exploration. The Journal of Alternative and Complementary Medicine, New York, v. 8, n. 3, p. 371-377, 2002.

BRASIL. Conselho Nacional de Secretários de Saúde. Assistência de média e alta complexidade no SUS. Brasília: CONASS, 2007. Disponível em: <http://bvsms.saude. gov.br/bvs/publicacoes/colec_progestores_livro9.pdf>. Acesso em: 1 jun. 2016.

BRASIL. Secretaria de Atenção Saúde. Política Nacional de Promoção da Saúde. Brasília: Ministério da Saúde, 2010. Disponível em: <http://bvsms.saude.gov.br/bvs/ publicacoes/politica_nacional_promocao_saude_3ed. pdf>. Acesso em: 1 jun. 2016.

BRUNELLO, M. I. B. Terapia ocupacional e grupos: uma análise da dinâmica de papéis em um grupo de atividade. Revista de Terapia Ocupacional da USP, São Paulo, v. 13, n. 1, p. 9-14, 2002. 
CALDEIRA, V. A.; MONTILHA, R. C. L.; NOBRE, M. I. R. S. Grupo de espera no processo de reabilitaçáo de pessoas com deficiência visual: contribuiçóes da terapia ocupacional. Cadernos de Terapia Ocupacional da UFSCar, São Carlos, v. 11, n. 2, p. 95-105, 2003.

CALLEGARO, D.; LINO, A. M. M.; MARCHIORI, P. E. Esclerose múltipla e outras doenças desmielinizantes do sistema nervoso central. In: MARTINS, M. A. et al. Clínica médica. Barueri: Manole, 2009. p. 449-478.

CARVALHO, Y. M. Promoção da saúde, práticas corporais e atenção básica. Revista Brasileira Saúde da Familia, Brasília, v. 7, n. 11, p. 33-45, 2006.

FERRIGNO, I. S. V. Reflexóes sobre as questôes do corpo na relação terapêutica. Revista de Terapia Ocupacional da Universidade de São Paulo, São Paulo, v. 1, n. 1, p. 27-32, 1990.

GIL, A. C. Métodos e técnicas de pesquisa social. São Paulo: Editora Atlas, 2006.

LEFÉVRE, F.; LEFÉVRE, A. M. C. O discurso do sujeito coletivo: um novo enfoque em pesquisa qualitativa (Desdobramentos). Caxias do Sul: EDUCS, 2003.

LÜDKE, M.; ANDRÉ, M. E. D. A. Pesquisa em educação: abordagens qualitativas. São Paulo: Editora Pedagógica e Universitária Ltda, 1988.

MALTA, D. C.; MERHY, E. E. O percurso da linha do cuidado sob a perspectiva das doenças crônicas não transmissíveis. Interface - Comunicação, Saúde, Educaçâo, Botucatu, v. 14, n. 34, p. 593-605, 2010.

MENEGHIN, M. C.; REIS, T. L.; SOARES, L. B. T. Atendimento de uma criança com ambliopia em terapia ocupacional: contribuição do método Meir Schneider de autocura. Cadernos de Terapia Ocupacional da UFSCar, São Carlos, v. 14, n. 2, p. 84-90, 2006.

RATEY, J. J. O cérebro - um guia para o usuário: como aumentar a saúde, a agilidade e a longevidade de nossos cérebros através das mais recentes descobertas científicas. Rio de Janeiro: Objetiva, 2002.

SAITO, C. M.; CASTRO, E. D. Práticas corporais como potência da vida. Cadernos de Terapia Ocupacional da UFSCar, São Carlos, v. 19, n. 2, p. 177-188, 2011.
SAMEA, M. O dispositivo grupal como intervenção em reabilitação: reflexôes a partir da prática em terapia ocupacional. Revista de Terapia Ocupacional da Universidade de São Paulo, São Paulo, v. 19, n. 2, p. 85-90, 2008.

SANTOS, L. M. et al. Grupos de promoção à saúde no desenvolvimento da autonomia, condiçóes de vida e saúde. Revista Saúde Pública, São Paulo, v. 40, n. 2, p. 346-52, 2006.

SCHNEIDER, M. Movimento para a autocura. São Paulo: Cultrix, 2005.

SCHNEIDER, M.; LARKIN, M. O.; SCHNEIDER, D. Manual de autocura: método Self-Healing. São Paulo: Triom, 1998.

SCHNEIDER, M.; LARKIN, M.; SCHNEIDER, D. Manual de autocura: patologias específicas - método Self-Healing 2a Parte. São Paulo: Triom, 1999.

TAVARES, A. A. et al. (Re) Organização do cotidiano de indivíduos com doenças crônicas a partir da estratégia de grupo. Cadernos de Terapia Ocupacional da UFSCar, São Carlos, v. 20, n. 1, p. 95-105, 2012.

TOLDRÁ, R. C. et al. Promoção da saúde e da qualidade de vida com idosos por meio de práticas corporais. O Mundo da Saúde, São Paulo, v. 38, n. 2, p. 159-168, 2014.

TOLDRÁ, R. C. Terapia ocupacional e o método Self-Healing: criando possibilidades de viver o corpo. In: PÁDUA, E. M. M.; MAGALHÃES, L. V. Casos, memórias e vivências em terapia ocupacional. Campinas: Papirus, 2005. p. 97-114.

TOLDRÁ, R. C.; SOUTO, A. C. F.; PIMENTEL, P. P. Autocuidado e prevenção de incapacidades para pessoas com esclerose múltipla e outros diagnósticos: aperfeiçoando e ampliando sua utilização. In: PRCEU; USP. Catálogo projetos 2012-2013: aprender com cultura e extensão. São Paulo: Rettec Artes Gráficas e Editoria, 2013. p. 147-147.

TUROLLA, A. C. S.; GEBRAEL, T. L. R.; NASCIMENTO, B. A. A contribuição do método Meir Schneider - Self-healing em um caso de osteoartrose de mãos. Revista de Terapia Ocupacional da Universidade de São Paulo, São Paulo, v. 26, n. 1, p. 83-92, 2015.

\section{Contribuição dos Autores}

Paula Pozzi Pimentel foi responsável pela elaboração de registros, transcrição e análise dos documentos e redação do texto. Rosé Colom Toldrá foi responsável pela concepção e condução da pesquisa, participação na análise e revisão final do texto. Todos os autores aprovaram a versão final do texto.

\section{Fonte de Financiamento}

Bolsa do Programa de Iniciação Científica (PIBIC) da FMUSP.

\section{Notas}

${ }^{1}$ Aprovação do Comitê de Ética em Pesquisada Faculdade de Medicina da USP, protocolo no 243/11, pesquisa denominada "Atenção à saúde e reabilitação de média complexidade à pessoa com deficiência física no âmbito da terapia ocupacional: perfil, demandas e açóes". 